\title{
The expression of personality among adolescents exposed to community interpersonal violence
}

\author{
Maretha J. VISSER* \\ Nicoleen COETZEE \\ Marleen CLAASSEN
}

Department of Psychology, University of Pretoria

\author{
* Corresponding author: \\ Prof Maretha Visser, Department of Psychology, University of Pretoria, Pretoria. \\ Maretha.Visser@up.ac.za
}

\begin{abstract}
The high level of crime in South Africa affects many adolescents. Experience of community interpersonal violence affects the social, emotional and cognitive functioning of adolescents and could have an impact on their personality development. The aim of the study was to explore possible differences in the expression of personality between adolescents exposed to community interpersonal violence and those not exposed to such violence. The sample comprised 183 grade 12 learners from a secondary school in a middle class community in Gauteng. Participants were divided into two groups: adolescents who reported exposure to community interpersonal violence $(n=93)$ and those who did not report exposure to such violence $(\mathrm{n}=90)$. Both groups completed the 16 Personality Factor and Posttraumatic Diagnostic Scales. Differences between the groups were explored using a one-way betweengroups multivariate analysis of variance (MANOVA) and t-tests for independent groups. Results indicated statistically significant differences between the two groups on Factor $G$
\end{abstract}


(rule consciousness), Factor I (emotional sensitivity) and Factor Q4 (anxiety). Adolescents exposed to interpersonal violence reported higher levels of posttraumatic stress disorder (PTSD) symptoms than the control group. The group that experienced PTSD symptoms differed more in terms of personality functioning (Factor I and Q4). Violence-exposed adolescents experienced more emotional volatility, difficulty to regulate emotions, anxiety and sensitivity to environmental stressors than those not exposed to such violence. Although causality cannot be assumed, it is possible that exposure to community interpersonal violence, which could result in PTSD symptoms, has implications for the personality development of adolescents. Interventions for adolescents exposed to interpersonal violence are recommended to prevent the development of PTSD symptoms.

Keywords: Adolescent, community interpersonal violence, personality, posttraumatic stress, psychosocial effect, sixteen personality factor questionnaire

\section{Introduction}

A large number of South African adolescents are affected by interpersonal violence in their communities (Shields, Nadasen, \& Pierce, 2008). Research indicated that more than a third of the South African population had been exposed to some form of violence by 2008 (Kaminer, Grimsrud, Myer, Stein, \& Williams, 2008). The key crime trends for the period 2013/2014 depicted a murder rate of 32.2 per 100000 of the population, which is about five times higher than the global average of 6.9 murders per 100000 . The prevalence of violent property crimes were 225 per 100000 of the population, public robberies were 133 per 100 000 and house robberies, where people are attacked by armed gangs while they are in their homes, were 37 per 100000 . Various crimes increased during the year under review, for example vehicle hijacking increased by $5.4 \%$, public robberies by $4.4 \%$ and house robberies 
by $7.1 \%$ (Institute for Security Studies and Africa Check, 2014). The experience of interpersonal violence is thus common in South African communities.

Adolescents' exposure to community interpersonal violence is a serious problem since it is known that such exposure has negative consequences for the adolescent's physical, emotional and academic development (Cisler, Begle, Amstadter, Resnick, Danielson, Saunders, \& Kilpatrick, 2012; Margolin, Vickerman, Oliver, \& Gordis, 2010).

The World Report on Violence and Health (WRVH) defines violence as "the intentional use of physical force or power, threatened or actual, against oneself, another person, or against a group or community, which either results in, or has a high likelihood of resulting in injury, death, psychological harm, mal-development, or deprivation" (WHO, 2011). The WRVH presents a typology of violence which can be a constructive way to comprehend the various contexts in which violence occurs and the interactions between types of violence (Figure 1).
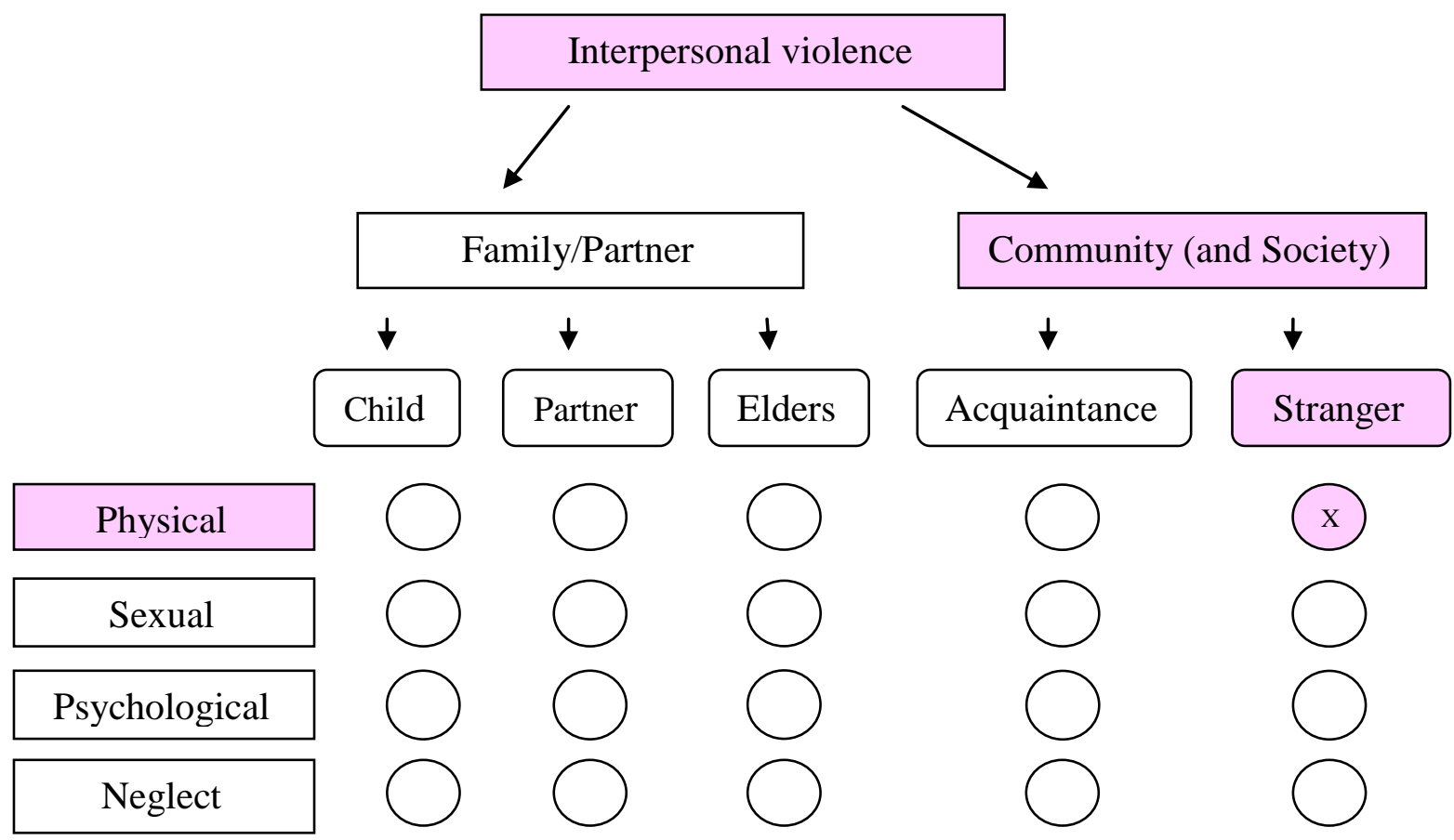

Figure 1. Typology of Interpersonal violence (Adapted from: Global Campaign for Violence prevention) 
For the purpose of the study, community interpersonal violence (highlighted in figure 1) was defined as physical violence that occurs in the community and is committed by a stranger/strangers resulting in injury, death or psychological harm. Community violence refers to violence experienced in society by individuals from the same geographical setting or from other or distant regions. In this context community interpersonal violence refers to being a victim or experiencing violence such as assault by strangers, vehicle hijacks, property crimes, shooting or murder. This definition does not include domestic violence, child abuse or sexual violence. Community interpersonal violence was the most prominent form of violence experienced by adolescents in a middle class community in South Africa (Claassen, 2015).

Interpersonal violence experienced in childhood and adolescence is associated with numerous psychosocial and adjustment problems, including low self-esteem, anxiety, delays in emotional processing, problems in social interaction, speech and language problems, and intellectual and behavioural difficulties (Cisler et al., 2012; Gil \& Caspi, 2006; Lynch, 2003; Mathews, Dempsey, \& Overstreet, 2009; Perkins \& Graham-Bermann, 2012). It is important to know whether the effect of violence on the psychological, biological and cognitive functioning of the adolescent (Margolin et al., 2010) influences the personality development of the adolescent.

Personality can be conceptualized as a configuration of cognitions, emotions and customs activated when situations excite their expression and determine the individual's unique adjustment to the world (Triandis \& Suh, 2002). It could be described as the dynamic organization of the psychological and physical systems within the person that motivate the person's patterns of actions, thoughts and emotional state (Carver \& Connor-Smith, 2010). While personality has traditionally been conceptualised as a stable trait, there is accumulating evidence that personality can change over time. Age and experience of life events are factors 
that affect changes in personality (Jeronimus, Ormel, Aleman, Penninx, \& Riese, 2013; Specht, Egloff, \& Schmukle, 2011; Triandis \& Suh, 2002). Longitudinal research (Jeronimus et al., 2013; Jeronimus, Riese, Sanderman, \& Ormel, 2014) found that negative life events are associated with small, but persistent, increases in neuroticism scores (on the Big Five personality scale) which persist a decade later. High neuroticism is associated with psychopathology and physical health problems. This research also showed that childhood adversity was associated with neuroticism in adulthood. This was explained by the influence child adversity has on the emotional reactivity in brain functioning (Bosch, Riese, Reijneveld, Bakker, Verhulst, Ormel, \& Oldehinkel, 2012).

To date limited research has explored the impact of exposure to interpersonal violence on personality (Specht et al., 2011). Moreover, no research results were found regarding exposure to interpersonal violence and personality as assessed by the 16 Personality Factor Inventory (16PF) (Cattell, 1989). An overview of relevant literature suggested that the experience of interpersonal violence may have the most significant impact on the following personality factors:

Factor G (Expedient - Rule-conscious)

Individuals with a low $\mathrm{G}$ tend to have trouble in situations that require conformance to rules and regulations (Craig, 1999). They may disrespect social and external rules and regulations and feel few obligations to others. They tend to be careless, indolent, undependable and indulgent (Craig, 1999; Landman, 1992). A combination of factors G- and $\mathrm{O}+$ suggests that the individual may break or stretch rules and then feel guilty about it. This combination may predict unconventional behaviour (Craig, 1999). A low G may propose a plea for help. Adolescents exposed to interpersonal violence develop a sense of learned 
helplessness, which may seriously affect mood and the development of a sense of efficacy and self-control, indicated by Factor G.

Factor I (Unsentimental - Sensitive)

Individuals with a high I tend to be intuitive and make judgements based on subjective impressions rather than their rational abilities. They tend to be vulnerable to perceived stress and wish to avoid conflict, to feel insecure and unrealistic and to be temperamental and seek help and sympathy (Craig, 1999; Landman, 1992). Being compassionate and sensitive, they are attuned to their own areas of vulnerability (Cattell, 1989; Craig, 1999; Landman, 1992). Factor I is of particular importance in this study, since it might reflect the way that victims of interpersonal violence habitually process information.

Factor O (Self-assured - Apprehensive)

A high $\mathrm{O}$ suggests psychological distress, referring to anxiety and depression. Individuals with a high score tend to worry needlessly, are depressed, feel worthless and inadequate, have a vague sense of dread and have low self-esteem (Cattell, 1989; Craig, 1999; Landman, 1992). They tend to be emotionally unstable and overly sensitive to criticism which tends to make them depressed and to lack self-acceptance. They are emotionally troubled and prone to guilt feelings without reasonable cause, cry easily and feel lonely (Cattell, 1989; Craig, 1999; Landman, 1992).

Factor Q4 (Relaxed - Tense)

A high score suggests free-floating anxiety, particularly in the presence of insecurity. Individuals with a high Q4 score tend to be restless, tense, impatient, anxious and emotionally volatile. They feel frustrated and maintain a level of excitement and tension which interfere with their functioning (Cattell, 1989; Craig, 1999; Landman, 1992). Research 
concludes that the stress, anxiety and fear generated by exposure to violence interfere with significant normal developmental tasks (Salzinger, Feldman, Stockhammer, \& Hood, 2002).

The above mentioned potential changes in the expression of personality could alter the adaptive functioning of the adolescent exposed to interpersonal violence. The concept 'adaptive functioning' refers to how effectively individuals cope with common life demands and how well they meet the standards of personal independence expected of someone of their particular age group, socio-cultural background and community setting (APA DSM-5, 2013). The experience of interpersonal violence may increase adolescents' vulnerability to develop anxiety, depression and posttraumatic stress disorder (PTSD) (Perkins \& Graham-Bermann, 2012).

Symptoms related to PTSD include re-experiencing the trauma, avoidance reactions and increased arousal. These symptoms result in significant difficulty to regulate one's emotions and behaviour (Matthews et al., 2009). When exposed to incidents of interpersonal violence, the expectation is that certain primary personality factors will reflect changes, particularly those primary factors that are highly sensitive to environmental experience which has an impact on the hypothalamic-pituitary-adrenal (HPA) axis. The HPA axis and sympathetic-adrenal-medullary system are critical in promoting adaptive responses to stress, anxiety or fear, thus contributing to the regulation of the stress response (Bosch et al., 2012; De Kloet, Vermetten, Gouze, Kavelaars, Heijnen, \& Westenberg, 2006).

The objective of the study was to explore if there are differences in the expression of personality between adolescents exposed to community interpersonal violence and those not exposed to such violence. Additionally, the expression of personality of adolescents who report symptoms of PTSD after exposure to violence was compared with those not exposed to violence. 


\section{METHOD}

\section{Research design}

A cross-sectional research design was used. Since this design involves measuring and then comparing different groups concurrently (Gravetter \& Forzano, 2009), the findings of the study could not be used to determine causality or predict future behaviour.

\section{Participants}

A sample of convenience was drawn from a public secondary school in a middle class community in Gauteng. This sample formed a fairly homogeneous cohort in terms of culture and environment. All the Grade 12 learners who were willing, completed a self-reporting questionnaire posing questions on their exposure to various kinds of violence. From their responses, two groups of learners were identified: Group 1 consisted of all the learners that reported exposure to some form of community interpersonal violence during the past 5 years $(n=93)$. Group 2 consisted of learners that did not report exposure to violence $(n=90)$. Learners who reported that they were exposed to violence other than community interpersonal violence (such as domestic or sexual violence) and those that reported that they witnessed violence, but were not directly involved, were excluded from the study. This was done to limit confounding factors that may influence valid conclusions related to community interpersonal violence. The characteristics of the sample is provided in Table 1.

Table 1. Descriptive statistics of the sample

\begin{tabular}{|c|c|c|c|}
\hline & \multirow[t]{2}{*}{ Mean age } & \multicolumn{2}{|c|}{ Gender } \\
\hline & & Male & Female \\
\hline $\begin{array}{l}\text { Group } 1 \\
(\mathrm{n}=93)\end{array}$ & 18 years 7 months & $54(58 \%)$ & $39(42 \%)$ \\
\hline $\begin{array}{c}\text { Group } 2 \quad(\mathrm{n}= \\
90)\end{array}$ & 18 years 9 months & $47(52 \%)$ & $43(48 \%)$ \\
\hline
\end{tabular}




\section{Measurement instruments}

The following measurement instruments were used:

Self-reporting questionnaire. This questionnaire served as a screening instrument. It was administered to all Grade 12 learners who were willing to participate. It provided information on the biographical details of the participants indicating their gender and age. Questions were asked regarding their exposure to various types of violence the past five years: interpersonal violence (assault, robbery, hijack), domestic violence or sexual violence. Learners who indicated that they were exposed to violence, had to answer questions on the type of violence they experienced, when it happened and if they were directly involved or witnessed violence happening to someone else. The learners' responses to these questions were used to select the two groups involved in the research.

The following instruments were administered to learners in Groups 1 and 2:

The 16 Personality Factor Questionnaire (16PF). The 16PF was originally developed by Raymond Cattell, based on his strong background in physical science (Cattell \& Mead, 2008; Gorard \& Taylor, 2004). The 16PF provides a comprehensive assessment of a wide range of personality dimensions. It measures basic personality concepts that contribute to an organized and integrated body of practical and theoretical knowledge in the clinical, educational, industrial and basic research fields (Cattell, Eber, \& Tatsuoka, 1970). The 16PF is unique in that its trait definitions were not forcefully restricted for reasons of statistical convenience (Cattell \& Schuerger, 2003). The primary scales provide an in-depth picture of the unique personality dynamics (Cattell \& Mead, 2008). The 16PF5 standardised for a South African population and used in this research, displays internal consistency higher than those of the fourth edition on which it was based, for all primary scales, especially for factors L, M, N and Q3 (Scherrer, van Rooyen, de Beer, Heyns, van der Merwe, \& Knoetze, 2004). The Cronbach Alpha reliability coefficients for the primary factors were between 0.80 and 
0.70, with a mean value of 0.76 (Scherrer et al., 2004). Test users in South-Africa can rely on local and international research findings to justify the appropriateness of using the $16 \mathrm{PF}$ (Abrahams \& Mauer, 1999).

The Posttraumatic Diagnostic Scale (PDS). The PDS has been used in a broad range of clinical and research contexts with a high degree of confidence. The PDS (Foa, 1995; Foa, Cashman, Jaycox, \& Perry, 1999) is a 31-item self-report measure that assesses the occurrence of a number of posttraumatic stress symptoms. The PDS total symptom severity scale displays high internal consistency, test-re-test reliability and convergent validity with other measures of PTSD diagnosis and severity (Moser, Hajcak, Simons, \& Foa, 2007). In this study highly acceptable Cronbach alpha scores, ranging from 0.86 to 0.95 , were obtained for the subscales of the PDS.

\section{Procedure}

After ethical clearance and permission to do the research was obtained, the project was explained to the Grade 12 learners at the target school. Parents were informed about the project through an information sheet and signed informed consent forms if they agree that their child could participate in the study. The self-reporting questionnaire was administered to all willing Grade 12 learners in their register classes. Based on their responses learners were divided into two groups ex post facto. Learners in the two groups $(n=183)$ completed the 16 PF and the PDS in an afternoon after school. The scores of learners in the two groups were compared statistically.

\section{Statistical analysis}

The differences in scores on the four personality traits of the $16 \mathrm{PF}$ for the groups exposed and not exposed to violence were compared using Multivariate Analysis of Variance (MANOVA) and post hoc pairwise comparisons (Pallant, 2010). The PDS scores of the two groups were compared using an independent samples t-test. A second MANOVA was used 
to investigate which personality factors would yield significant differences between high and low scores on the PDS. The statistical analysis was done using SPSS Windows version 20.

\section{Ethical considerations}

The research was approved by the Ethics Committee of the Faculty of Humanities at the University of Pretoria and the principal of the specific school. Informed consent was obtained from adolescents and parents. Participation was voluntary and privacy, confidentiality and anonymity of the participants were respected at all times.

\section{RESULTS}

The adolescents who were exposed to community interpersonal violence reported that they mostly experienced armed house robbery $(62.4 \%)$, car hijacking $(18.3 \%)$ and physical assault (19.3\%). In order to determine if significant differences occur in the expression of personality between adolescents exposed to incidents of community interpersonal violence and adolescents not exposed to such violence, a MANOVA was performed (Pallant, 2010). Statistically significant differences were observed between the two groups on the 16PF factors investigated in the study, yielding $\mathrm{F}(4,178)=3.72, \mathrm{p}=0.006$; Wilks' Lamda $=0.92$; partial eta squared $=0.08$. In order to determine where these differences occurred, tests for between subjects effects were conducted (see Table 2).

Table 2. Tests of Between-subjects effects

\begin{tabular}{lccccccc}
\hline \multicolumn{7}{c}{ Tests of Between-Subjects Effects } \\
\hline Source & $\begin{array}{c}\text { Dependent } \\
\text { Variable }\end{array}$ & $\begin{array}{c}\text { Type III Sum of } \\
\text { Squares }\end{array}$ & Df & Mean Square & F & p-value & $\begin{array}{c}\text { Partial eta } \\
\text { squared }\end{array}$ \\
\hline \multirow{4}{*}{ Group } & G & 25.104 & 1 & 25.104 & 6.645 & 0.011 & 0.035 \\
& I & 20.900 & 1 & 20.900 & 6.773 & 0.010 & 0.036 \\
& O & 16.289 & 1 & 16.289 & 3.093 & 0.080 & 0.017 \\
& Q4 & 23.105 & 1 & 23.105 & 7.452 & 0.007 & 0.040 \\
\hline
\end{tabular}

When applying a Bonferonni adjustment to the results indicated in Table 2, it appears that statistically significant differences for primary factor scales $G(p=0.011), I(p=0.010)$ 
and Q4 ( $\mathrm{p}=0.007)$ occurred between the two groups. The magnitude of the differences between the two groups on these three factors indicated a moderate effect size (see Table 2).

The second objective of the study was to determine if the personality expression of adolescents who reported posttraumatic stress symptoms after exposure to incidents of community interpersonal violence, differed from those who have not experienced such violence. Firstly, the PDS scores of Group 1 and 2 were compared using independent samples t-tests (see Table 3).

Table 3. Descriptive statistics and t-test results on PDS scores

\begin{tabular}{|c|c|c|c|c|c|c|c|c|}
\hline Subscale & Group & Mean & $\begin{array}{c}\text { Std. } \\
\text { Deviation }\end{array}$ & t-value & p-value & $\begin{array}{c}\text { Effect } \\
\text { size }\end{array}$ & $\begin{array}{r}95 \\
\text { Lower } \\
\text { Bound }\end{array}$ & \\
\hline \multirow[t]{2}{*}{ Re-experiencing } & $2(n=90)$ & 4.23 & 4.16 & -2.64 & 0.009 & 0.04 & -3.26 & -0.47 \\
\hline & $1(n=93)$ & 6.10 & 5.33 & & & & & \\
\hline \multirow[t]{2}{*}{ Avoidance } & 2 & 5.90 & 5.75 & -2.84 & 0.005 & 0.04 & -4.60 & -0.83 \\
\hline & 1 & 8.61 & 7.11 & & & & & \\
\hline \multirow[t]{2}{*}{ Arousal } & 2 & 4.91 & 5.01 & -2.90 & 0.004 & 0.04 & -3.77 & -0.71 \\
\hline & 1 & 7.15 & 5.43 & & & & & \\
\hline \multirow[t]{2}{*}{ Total score } & 2 & 15.04 & 13.63 & -3.05 & 0.003 & 0.06 & -11.23 & -2.40 \\
\hline & 1 & 21.86 & 16.54 & & & & & \\
\hline
\end{tabular}

Minimum score $=0$; maximum total score $=72$

The results of the t-tests (Table 3$)$ for the PDS as a whole $(\mathrm{M}=21.86$ versus $\mathrm{M}=$ 15.04; $\mathrm{p}<0.001$ ) as well as those obtained for all the subscales of the PDS (Re-experiencing, Avoidance and Arousal) confirmed that adolescents in Group 1 (who were exposed to interpersonal violence) experienced more PTSD symptoms than adolescents in Group 2. The magnitude of the differences in the means for each of the subscales as well as the scale total indicated a moderate effect size (see Table 3). The relative high scores of Group 2 on the PDS should be noted as this group was not exposed to such violence but appeared to be experiencing some posttraumatic stress symptoms.

To determine whether adolescents who experienced high levels of PTSD symptoms expressed their personality different from others, the sample was divided into three groups: 
- Group 1A - adolescents in Group 1 who experienced high levels of posttraumatic stress symptoms (PTSD score $\geq 36$ as the midpoint of the scale) $(n=23)$;

- Group 1B - adolescents in Group 1 who experienced low levels of posttraumatic stress symptoms $($ PTSD score < 36) $(\mathrm{n}=69)$;

- Group 2 - adolescents in Group 2 were not exposed to interpersonal violence $(n=90)$.

The three groups were compared by means of MANOVA. Statistically significant differences were observed between the three groups, $\mathrm{F}(8,352)=3.1, \mathrm{p}=0.002$; Wilks' Lamba $=0.87$; partial eta squared $=0.07$. In order to determine where these differences occurred, pairwise comparisons were conducted (see Table 4).

Table 4. Summary of pairwise comparisons

\begin{tabular}{|c|c|c|c|c|c|c|}
\hline \multirow[b]{2}{*}{$\begin{array}{c}\text { Dependent } \\
\text { Variable }\end{array}$} & \multirow{2}{*}{$\begin{array}{c}\text { (I) } \\
\text { PDS Total }\end{array}$} & \multirow{2}{*}{$\begin{array}{c}(\mathrm{J}) \\
\text { PDS Total }\end{array}$} & \multirow{2}{*}{$\begin{array}{c}\text { Mean } \\
\text { Difference (I- } \\
\text { J) }\end{array}$} & \multirow[b]{2}{*}{ p-value } & \multicolumn{2}{|c|}{ 95\% C.I. } \\
\hline & & & & & $\begin{array}{l}\text { Lower } \\
\text { bound }\end{array}$ & $\begin{array}{l}\text { Upper } \\
\text { bound }\end{array}$ \\
\hline \multirow{2}{*}{ I 16PF } & \multirow{2}{*}{$\begin{array}{c}\text { Group 1A High } \\
\text { PDS }\end{array}$} & $\begin{array}{c}\text { Group 1B Low } \\
\text { PDS }\end{array}$ & 0.97 & 0.064 & -0.04 & 1.98 \\
\hline & & $\underset{\text { violence }}{\text { Group } 2}$ No & 1.39 & 0.002 & 0.41 & 2.37 \\
\hline \multirow{2}{*}{ Q4 16PF } & \multirow{2}{*}{$\begin{array}{c}\text { Group 1A High } \\
\text { PDS }\end{array}$} & $\begin{array}{l}\text { Group 1B Low } \\
\text { PDS score }\end{array}$ & 0.97 & 0.063 & -0.04 & 1.98 \\
\hline & & $\begin{array}{l}\text { Group } 2 \text { No } \\
\text { violence }\end{array}$ & 1.47 & 0.001 & 0.49 & 2.45 \\
\hline
\end{tabular}

When applying a Bonferonni adjustment to the results indicated in Table 4, it appears that statistically significant differences occurred between adolescents of Group 1A experiencing PTSD symptoms and adolescents who did not experience community interpersonal violence (Group 2) on Factors I+ and Q4+. This result was significant despite the relatively small sample who experience post traumatic symptoms $(\mathrm{N}=23)$. There were no significant differences in the group of adolescents who were exposed to violence but did not report PTSD symptoms and the adolescents not exposed to violence. PTSD symptoms can therefore play a role in the differences in expression of personality. Unfortunately the possible 
mediating effect of PTSD could not be confirmed by using path analysis, since the data set was too small.

\section{DISCUSSION}

\section{Differences in expression of personality}

The results revealed that adolescents exposed to interpersonal violence had a higher I score (Thinking versus Feeling) than those not exposed to such violence $(M=4.72$ vs $M=4.04 ; p$ $<0.01)$. This means that adolescents exposed to community interpersonal violence process information and respond to their environment in a more emotional way than others and may be inclined to exclude reasoning during evaluation and decision-making. The adolescents in Group 1 may be more emotional, changeable and indecisive. Interpersonal difficulty may stem from the adolescents' need for more than average amounts of reassurance and support (Cattell \& Schuerger, 2003).

The results showed a significant difference between the groups on Factor G (Group 1, $\mathrm{M}=4.56$; Group 2, $\mathrm{M}=5.30, \mathrm{p}<0.01$ ). Factor $\mathrm{G}$ (Expedient vs Rule-conscious) reflects superego strength and moral values. If an adolescent's G-score is low, it suggests indecisiveness and a tendency to give up easily (Landman, 1992). The adolescent may be under-controlling and display behaviour such as aggression, self-injurious behaviour and avoidance reactions (Fowler, Tompsett, Braciszewski, Jacques-Tuira, \& Baltes, 2009; Price, Higa-McMillan, Kim, \& Frueh, 2013).

The results also indicated a significant difference between the groups on Factor Q4 (Group 1, M = 6.68; Group $2 \mathrm{M}=5.97, \mathrm{p}<0.01$ ). Factor $\mathrm{Q} 4+$ measures the excitement and tension that accompany autonomic arousal and nervous tension in generalized fears. Q4 is also associated with the frustration responses that range from anger and aggression to anxiety and depression (Cattell \& Schuerger, 2003). The implication of high anxiety levels for the 
adolescent could manifest as problems in mental efficiency, such as slowing, scrambling or blocking thought processes or having words and memory failure. These problems enhance distractibility and are exacerbated by depression (Lezak, Howieson, \& Loring, 2004).

The results thus showed differences between the two groups in terms of emotional volatility, regulation of emotions, anxiety and sensitivity to environmental stressors - all factors related to neuroticism (Jeronimus et al., 2013). The research design did not allow for assumptions of causality, therefore it can only be concluded that there is a relationship between personality characteristics involving emotional reactions and direct exposure to interpersonal violence among adolescents. Other research confirmed the negative consequences of exposure to violence for emotional, social and cognitive functioning of adolescents (Cisler et al., 2012; Donnelly \& Amaya-Jackson, 2002; Gil \& Caspi, 2006; Mathews et al., 2009; Margolin et al., 2010; Perkins \& Graham-Bermann, 2012).

\section{Posttraumatic stress and the expression of personality}

Adolescents exposed to community interpersonal violence reported significantly more symptoms of PTSD, than adolescents not exposed to similar violence. The relative high scores of Group 2 on the PDS should be noted as this group was not exposed to such violence but still experienced some posttraumatic stress symptoms. It must be considered that South Africa is currently characterised by violence and conflict, creating a highly stressful environment to live in (Seedat, van Niekerk, Jewkes, Sulfla, \& Ratele, 2009). The typology of interpersonal violence (Figure 1) differentiates four modes in which violence

may be imposed: physical, sexual and psychological and neglect. It also differentiates contexts where violence take place. All these contexts have not been assessed in this particular study, but could influence PDS scores in both groups. 
The results in Table 4 showed that adolescents with high levels of PTSD symptoms (Group 1A) expressed their personality on factors I+ and Q4+ differently from those who did not experience community interpersonal violence (Group 2). They showed more emotional sensitivity and anxiety than other adolescents. The same was not found for adolescents exposed to interpersonal violence who did not report PTSD symptoms. Because of the small sample size we could not confirm this relationship through a path analysis. Data nevertheless indicates that PTSD symptoms may play a role in the relationship between personality characteristics related to emotional response patterns of adolescents exposed to interpersonal violence.

Additionally, this research showed that not all adolescents exposed to interpersonal violence differed from the control group in terms of expression of personality. Individual differences in brain processes and support structures may influence adolescents' reaction to interpersonal violence. It has been estimated that PTSD develops in $30 \%$ of adolescents who were victims of serious incidents of interpersonal violence (Hizli, Taskintuna, Isikli, Kilic, \& Zileli, 2009). If adolescents do not manage to deal effectively with the experience of interpersonal violence, PTSD symptoms can develop which may particularly result in negative implications for the adolescents' emotional and personality development.

The results were based on the self-reported experiences of a small sample of adolescents from a fairly homogenous middle class community. This limits the extent to which results can be generalised. The cross sectional design limited the scope of conclusions that can be drawn. Limited information were gathered regarding the severity, the time lapse and direct implications of the exposure to violence. The support the adolescents received after the incident is also unknown. The ex post facto nature of the research prevented the elimination of possible confounding variables. 
In an effort to understand causal patterns and individual differences after exposure to community interpersonal violence, a longitudinal study involving a larger cohort would be required. Adolescents exposed to various kinds of violence (figure 1) could also be included and compared. A more comprehensive assessment battery for personality development, PTSD and biological tests (like EEG, MRI or cortisol tests) should be used as collateral measurements to understand the development of PTSD, brain-behaviour relationship and the expression of personality. Such a design could clarify the relationship between variables and differences in unique sensitivity of adolescents exposed to violence as well as the diversity in brain functioning.

\section{Conclusion}

The results of this study suggest some significant differences in the expression of personality for adolescents exposed to incidents of community interpersonal violence compared to adolescents not exposed to such violence. Statistical significant differences were found for factors G, I and Q4. It was furthermore discovered that the group of adolescents exposed to violence that reported more PTSD symptoms differed more on factors I and Q4 than others not experiencing PTSD symptoms. These results demonstrated that adolescents exposed to interpersonal violence may experience more emotional volatility, difficulty in emotional regulation, anxiety and sensitivity to environmental stressors. The research results highlight that adverse life experiences, such as sudden, unexpected community interpersonal violence, can negatively influence some adolescents' expression of personality, especially with regard to emotional sensitivity, reactivity and adaptive functioning. This may negatively impact their development.

The research results emphasized the urgency for providing appropriate treatment for adolescents exposed to violence. Teachers and practitioners should be made aware of the 
expression of these particular personality traits after exposure to violence for referral and treatment purposes. Because of high levels of violence in communities it is suggested that adolescents exposed to violence receive treatment soon after the incident (Donnelly, Kovacova, \& Osofsky, 2005) to prevent the development of PTSD symptoms which could intensify the negative consequences of exposure to violence. Treatment can promote positive ways of coping. It is necessary to examine the sources of resilience and community strengths that extend beyond the individual.

\section{REFERENCES}

American Psychiatric Association (2013). Diagnostic and Statistical Manual of Mental Disorders fifth edition (DSM-5). American Psychiatric Association Publishing.

Abrahams, F. \& Mauer, K.F. (1999). The comparability of the constructs of the 16 PF in the South-African context. Journal of Industrial Psychology, 25 (1), 53-59.

Bosch, N.M., Riese, H., Reijneveld, S.A., Bakker, M.P., Verhulst, F.C., Ormel, J., \& Oldehinkel, A.J. (2012). Timing matters: long-term effects of adversities from prenatal period up to adolescence on adolescents' cortisol stress response. The TRAILS study. Psychoneuroendocrinology, 37, 1439-1447.

Carver, C.S. \& Connor-Smith, J. (2010). Personality and Coping. Annual Review of Psychology, 61, 679-704.

Cattell, H.B. (1989). The 16PF: Personality in Depth. Illinois, Champaign: Institute for Personality and Ability Testing, Inc.

Cattell, R. B., Eber, H. W., \& Tatsuoka, M. M. (1970). Handbook for the 16 PF. Champaign, IL: Institute for Personality and Ability Testing.

Cattell, H. E., \& Mead, A. D. (2008). The sixteen personality factor questionnaire (16PF), The SAGE handbook of personality theory and assessment, 2, 135-178. 
Cattell, H.E.P. \& Schuerger, J. M. (2003). Essentials of 16 PF Assessment. John Wiley \& Sons, USA.

Cisler, J.M., Begle, A.M., Amstadter, A.B., Resnick, H.S., Danielson, C.K., Saunders, B.E. \& Kilpatrick, D.G. (2012). Exposure to interpersonal violence and risk for PTSD, depression, delinquency, and binge drinking among adolescents: Data from the NSA-R. Journal of Traumatic Stress, 25 (1), 33-40.

Claassen, M. (2015). The expression of personality among adolescents exposed to interpersonal violence. Unpublished Doctoral thesis. University of Pretoria.

Craig, R. J. (1999). Interpreting personality tests: a clinical manual for the MMPI-2, MCMI-III, CPI-R, and 16PF. New York: John Wiley \& Sons, NY 10158-0012.

De Kloet, C.S., Vermetten, E. Geuze, E., Kavelaars, A., Heijnen, C.J., \& Westenberg, H.G.M. (2006). Assessment of HPA, non-pharmacological challenge tests, a review. Journal of Psychiatric Research, 40, 550-567.

Donnelly, C.L. \& Amaya-Jackson, L. (2002). Posttraumatic stress disorder in children and adolescents. Paediatric Drugs, 4 (3), 159- 170.

Donnelly, J., Kovacova, A., \& Osofsky, J. (Eds.). (2005). Developing Strategies to Deal with Trauma in Children. Amsterdam: IOS Press.

Foa, E. B. (1995). Posttraumatic stress diagnostic scale. National Computer Systems.

Foa, E.B., Cashman, L., Jaycox, L., \& Perry, K. (1999). The validation of a self-report measure of posttraumatic stress disorder: The Posttraumatic Diagnostic Scale. Psychological Assessment, 9, (4), 445 - 451.

Fowler, P.J., Tompsett, C.J., Braciszewski, J.M., Jacques-Tuira, A.J., \& Baltes, B.B. (2009). Community violence: A meta-analysis on the effect of exposure and 
mental health outcomes of children and adolescents. Development of Psychopathology, 21, 227-259.

Gil, S. \& Caspi, Y. (2006). Personality traits, coping style, and perceived threat as predictors of posttraumatic stress disorder after exposure to a terrorist attack: A prospective study. Psychosomatic Medicine, 68 (6), 904-909.

Gorard, S. \& Taylor, C. (2004). Combining methods in educational and social research. Maidenhead: Open University Press.

Gravetter, F.J. \& Forzano, L.A.B. (2009). Research methods for the behavioral sciences. Belmont, USA: Wadsworth Cengage Learning.

Hizli, F.G., Taskintuna, N., Isikli, S., Kilic, C. \& Zileli, L. (2009). Predictors of posttraumatic stress in children and adolescents. Children and Youth Services Review, 31, $349-354$.

Institute for Security Studies and Africa Check (2014). Factsheet South Africa: Official Crime Statistics. (2014). Retrieved from

http://africacheck.org/factsheets/factsheet-south-africas-official-crime-statistics-for$\underline{201314}$

Jeronimus, B.F., Ormel, J., Aleman, A., Penninx, B. W. J. H., \& Riese, H. (2013). Negative and positive life events are associated with small but lasting change in neuroticism. Psychological Medicine, 1-13. doi:10.1017/S0033291713000159.

Jeronimus, B.F., Riese, H., Sanderman, R., \& Ormel, J. (2014). Mutual reinforcement between neuroticism and life experiences: A five-wave, 16-year study to test reciprocal causation. Journal of Personality and Social Psychology, 107 (8).

doi.org/10.1037/a0037009. 
Kaminer, D., Grimsrud, A., Myer, L., Stein, D.J., \& Williams, D.R. (2008). Risk for posttraumatic stress disorder associated with different forms of interpersonal violence in South Africa. Social Science and Medicine, 67 (10), 1589-1595.

Landman, J.P. (1992). Manual for the interpretation of the 16PF. Pretoria: Human Sciences Research Council.

Lezak, M.D., Howieson, D.B., \& Loring, D.W. (2004). Neuropsychological assessment, 4th edition. New York: Oxford University Press.

Lynch, S.M. (2003). Cohort and life-course patterns in the relationship between education and health: A hierarchical approach. Demography, 40 (2), 309-331.

Margolin, G., Vickerman, K.A., Oliver, P.H., \& Gordis, E.B. (2010). Violence exposure in multiple interpersonal domains: Cumulative and differential effects. Journal of Adolescent Health, 47, 198 - 205.

Mathews, T., Dempsey, M., \& Overstreet, S. (2009). Effects of exposure to community violence on school functioning: The mediating role of posttraumatic stress symptoms. Behaviour Research and Therapy, 47, 586 - 591.

Moser, J.S., Hajcak, G., Simons, R.F., \& Foa, E.B. (2007). Posttraumatic stress disorder symptoms in trauma-exposed college students: The role of trauma-related cognitions, gender, and negative affect. Journal of Anxiety Disorders, 21, 10391049.

Pallant, J. (2010). SPSS Survival Manual: A step by step guide to data analysis using the SPSS program. England: Open University Press.

Perkins, S. \& Graham-Bermann, S. (2012). Violence exposure and the development of school-related functioning: Mental health, neuro-cognition, and learning. Aggression and Violent Behaviour, 17, 89-98. 
Price, M., Higa-McMillan, C., Kim, S., \& Frueh, K.B. (2013). Trauma experience in children and adolescents: An assessment of the effects of trauma type and role of interpersonal proximity. Journal of Anxiety Disorders, 27, 652- 660.

Salzinger, S., Feldman, R.S., Stockhammer, T. \& Hood, J. (2002). An ecological framework for understanding risk for exposure to community violence and the effects of exposure on children and adolescents. Aggression and violent behaviour, $7,423-451$.

Scherrer, R., van Rooyen, J., de Beer, J., Heyns, A., van der Mewer, C., \& Knoetze, H. (2004). 16 Personality factor questionnaire (16 PF) Fifth edition, Training manual. Johannesburg: Jopie van Rooyen \& Partners.

Seedat, M., Van Niekerk, A., Jewkes, R., Suffla, S. \& Ratele, K. (2009). Violence and injuries in South Africa: prioritising an agenda for prevention. Health in South Africa, 5 (374), $1011-1019$.

Shields, N., Nadasen, K., \& Pierce, L. (2008). The effects of community violence on children in Cape Town, South Africa. Child Abuse and Neglect, 32, 589-601.

Specht, J., Egloff, B., \& Schmukle, S.C. (2011). Stability and change of personality across the life course: the impact of age and major life events on mean-level and rank-order stability of the Big Five. Journal of Personality and Social Psychology, 101(4), 86282. doi: $10.1037 / \mathrm{a} 0024950$.

Triandis, H.C. \& Suh, E.M. (2002). Cultural influences on personality. Annual Review of Psychology, 53, 133-160.

World Health Organisation (2011). Global Campaign for Violence prevention. Retrieved from http://www.who.int/violence prevention/approach/definition/en/ 